\title{
Registered International Sports Physical Therapist (RISPT): towards excellence in sports physiotherapy for the athlete
}

\author{
Colin Paterson ${ }^{1,2}$, Mario Bizzini ${ }^{3,4}$, Joachim Van Cant ${ }^{5,6}$ and Alexandre Rambaud ${ }^{7,8}$ \\ ${ }^{1}$ University of Brighton, School of Sports and Health Sciences, Brighton, UK, ${ }^{2}$ ACPSEM/Physios in Sport, ${ }^{3}$ Human Performance Lab, Schulthess Clinic, Zürich \\ Switzerland, ${ }^{4}$ Swiss Sports Physiotherapy Association, ${ }^{5}$ Université Libre de Bruxelles, Bruxelles, Belgium, ${ }^{6}$ Belgian Federation of Sports Physiotherapy, \\ ${ }^{7}$ Department of Clinical and Exercise Physiology, Sports Medicine Unity, University Hospital of Saint Etienne, Faculty of medicine, Saint-Etienne. France, \\ ${ }^{8}$ SFMKS-Lab, Société Française des Masseurs-kinésithérapeutes du Sport, Pierrefitte/Seine, France
}

DOI: $10.52057 /$ erj.v1i1.12

received : 2 December 2021

accepted: 19 December 2021

\section{Background ; IFSPT Competencies and RISPT}

$P^{\text {hysi }}$ hysiotherapy, as a profession, is always evolving and developing its knowledge and skill base, and in turn specialist areas of practice have developed. Physiotherapists and particularly Sports and Exercise Physiotherapy specialists require in-depth knowledge, skills and competence specific to this context and area of practice [1]. Sport physiotherapists are typically at the edge of the sport field, close to the injury but also close to the performance, which requires an increasingly high levels of expertise. The International Federation of Sports Physical Therapy (IFSPT) was formed in 2000 in recognition of the need for an international group to bring together national organisations representing sports physiotherapists. IFSPT is a recognised subgroup of World Physiotherapy (www.world.physio).

As part of an EU-funded Sports Physiotherapy for All project (SPA project that was completed in 2007 , sports physiotherapy competencies and standards were developed rigorously by a project team, researchers, and a group of international experts in conjunction with the IFSPT. Eleven sports physiotherapy competencies were developed and defined using benchmark statements relating to effective professional behaviours that integrate specific knowledge, skills, and attitudes specific to sports and exercise physiotherapy [2]. Subsequently standards were developed that describe the specific behavioural indicators of the level at which the competencies should be demonstrated, namely a minimum level of capability. Importantly, the minimum threshold is described at Master's level, which promotes individuals having extensive knowledge and skills that demonstrate critical reasoning, flexibility, creativity, independence and leadership [3]. The competencies take a broad stance and refer to athletes of all ability levels and refer to anyone who participates in sports and exercise from recreational through to elite level and those who undertake physical activity.

The IFSPT sports physiotherapy competency document (www.ifspt. org) brings with it many advantages including; a common understanding

Alexandre J.M. Rambaud, Campus Santé Innovations IRMIS, 42270 Saint-Priest en Jarez, France mail : alexandre.rambaud.kine@gmail.com ORCiD:

0000-0001-7194-7777 and description of the core professional roles and behaviours of sports physiotherapists, the promotion of professional mobility, use in quality assurance of services, clarity of role descriptions for employees, employers and general public, and as a tool for planning and delivering further professional development [1].

The IFSPT uses this document as a benchmarking tool as part of its process for approving member organisations professional development pathways, allowing members to become a Registered International Sports Physical Therapist (RISPT). Currently the IFSPT has 13 member countries with an approved development pathway, the first of these countries were approved in 2009 , and currently individuals can only become a RISPT via an approved country's pathway. IFSPT approved pathways require the evidencing of both formal and informal learning, typically an MSc to meet the master's level requirement, sports physiotherapy specific work experience and the use of reflective practice allowing individuals to evidence learning from a variety of events and scenarios. These requirements are consistent with the literature that highlights the need for regular deliberate practice, reflective practice and development of different knowledge types to support professional development and development of expertise [4, 5]. Fundamentally, IFSPT approved professional development pathways promote and support individuals to develop the required knowledge, skills and behaviours to become a specialist sports physiotherapist.

While RISPT status does not license an individual in other countries, it does notify that the individual has achieved the highest level of qualification in his or her country, meeting international IFSPT requirements. Benefits include a recognition of achievement on an international level, increased research and teaching opportunities, a positive effect on consultations and invited presentations, new job opportunities, opportunities for increased job responsibility and an increase in prestige within clinical and academic settings as well as professional associations and the community as a whole.

\section{French-speaking countries; RISPT implementation}

\section{The implementation of RISPT in Switzerland}

The Swiss Sport Physiotherapy Association (SSPA, www.sportfisio.ch), founded in 2002 as a non-profit organization, is a recognized subgroup 
of Physioswiss (the Swiss Association of Physiotherapy) and since 2004 a Member Organization of IFSPT. Currently the SSPA counts about 550 qualified sport physiotherapist members, and strongly recommends its members to keep a record of their continuing professional development (CPD). The SSPA has cooperation contracts with the Swiss Olympic Association (which includes the various Swiss sports federations) and the major national Universities of Applied Sciences offering MSc programs in sports physiotherapy.

In 2019, the SSPA developed national CPD guidelines (based on accreditation levels) for Swiss sports physical therapists, which was officially recognized by the IFSPT in January 2020. To become a SSPA member, any physiotherapist must fulfil the minimum SVSP requirements (according to Article 4 of the statutes) for membership. Each interested SSPA member can then apply for one of the three accreditation levels (A, B, C), which are based on the 11 IFSPT competencies and on defined criteria partially formulated in cooperation with the Swiss Olympic Association. The accreditation level $\mathrm{C}$ is required to work as a sports physiotherapist at national and international competitions and to be able to apply for the most important sports events (e.g. Olympic Games, European and World Championships). The accreditation levels B and A are required to be able to apply as a Chief Physiotherapist Officer for national selections as well as for the most important sporting events (e.g. Olympic Games, European and World Championships). The Level A membership, which implies the completion of a MSc Level education mapped to the IFSPT competencies, will entitle those SSPA members to individually apply for RIPST registration.

The SSPA accreditation system aims to enable Swiss sports PTs to provide evidence of CPD throughout their professional careers, and therefore aiming to higher standards of athlete's care in Switzerland. It is also a unique opportunity to enhance the cooperation with the Swiss Olympic Association, the Swiss national federations, and all other related partner societies (sports medicine, sports psychology, sports nutrition, coaching).

\section{The implementation of RISPT in Belgium}

The Belgian Federation of Sports Physiotherapy (BFSP, www.bfsp.be/fr) was founded in 2005 at the initiative of Professor Meeusen, a physiotherapist, from the Vrij Universiteit Brussel. The BFSP is recognized by Axxon (the Belgian Association of Physiotherapy) and by the IFSPT since 2019. The missions of the BFSP are to represent sport physiotherapists at national and international level; to promote education, research and development of sport physiotherapy; to promote the place of the sport physiotherapist in society, both in prevention and promotion of a healthy lifestyle based on physical activity and sport.

Since 2019, the BFSP developed a national membership classification according to international IFSPT recommendations and adapted to Belgian legislation. To become a BFSP member, any physiotherapist could apply for one of the three accreditation levels (Gold, Silver, Bronze), which are based on the 11 IFSPT competencies and on specific Belgian criteria. For example, to achieve "Gold" level accreditation, the physiotherapist must have successfully completed an academic certificate program in sport physiotherapy of 45 ECTS, to certify "Long Life Learning" in specific academic education incorporating the IFSPT competencies (continuing education in sport rehabilitation, supervised internship, scientific publications in the field of sport physiotherapy), to attest at least $75 \%$ of working time in sport physiotherapy based on the IFSPT competencies, and to attest participation in national or international sport physiotherapy congresses. Moreover, a sport physiotherapist reaching the "Gold" level can become a RISPT and be recognized at international level with IFSPT status.

\section{The implementation of RISPT in France}

The national organisation of sports physiotherapy in France is representing by the SFMKS (Société Française des Masseurs Kinésithérapeutes du
Sport, www.kinedusport.com). It is the result of the Société Française des Kinésithérapeutes du Sport born in 1969. Since the second IFSPT world congress in Belfast 2017, the SFMKS had the will to integrate with the IFSPT, and in August 2021 the SFMKS became an official member organisation. The 2022 project of the SFMKS is to develop and propose a CPD pathway for French physiotherapists to be able to gain recognition as a RISPT. In France, there is a complementary diploma in sports physiotherapy, but it does not fulfil all the items required by the IFSPT. Master of Science degrees (in the field of science, technology and health) exist and focus on athlete performance and injury prevention, but again, some items are missing from the curriculums. It is therefore planned to propose a complementary SFMKS CPD pathway that will be IFSPT approved.

Once SFMKS has an IFSPT approved pathway, a group of experts will be set up to oversee the internal application process; validate all the SPA items and the applicant's experience in sports physiotherapy. Mentoring will also be considered, and a portfolio could be envisaged, to ensure the companionship achieved. This mentoring is considered essential and will be a guarantee of quality for the athletes.

\section{Conclusion}

In the three projects in Switzerland, Belgium and France, the implementation of the SPA project and IFSPT requirements, leading to RISPT, is done differently according to the legislation of each country and the history of each association. This adaptation is very important, because in each country there are already regional specificities, mainly due to the language spoken, such as French. French-speaking therapists have difficulty reading scientific literature in English, but this gap seems to be closing rapidly. The support of the IFSPT and the inter-associative collaborations are the main actors, being attentive and benevolent to the exchanges and communications of non-English speakers.

In conclusion, the aim of RISPT is to ensure that athletes are cared for by ethical, anti-discriminatory and anti-doping sports physiotherapists who are aware of the latest best practice guidelines for optimal athlete care. Thanks to the IFSPT and the SPA project, these goals for as many athletes as possible will be possible, even for those who speak French!

\section{References}

[1] Catherine Bulley and Marie Donaghy. Sports physiotherapy competencies: the first step towards a common platform for specialist professional recognition. Physical therapy in sport, 6(2):103-108, 2005.

[2] Catherine Bulley and Marie Donaghy. Sports physiotherapy standards: A minimum threshold of performance. Physical therapy in sport, 6(4): 201-207, 2005.

[3] Scottish Credit. An introduction to the scottish credit and qualifications framework, 2003.

[4] Colin Paterson and Nicola Phillips. Developing sports physiotherapy expertise-the value of informal learning. International Journal of Sports Physical Therapy, 16(3):959, 2021.

[5] Nicola J Petty. Becoming an expert: a masterclass in developing clinical expertise. International Journal of Osteopathic Medicine, 18(3): 207-218, 2015. 